\title{
The higher risk for sperm DNA damage in infertile men
}

\author{
Kamil Gill' , Aleksandra Rosiak-Gill1,2, Joanna Jakubik¹, Lukasz Patorski 1,3, \\ Mariusz Lukaszuk ${ }^{4,5}$, Malgorzata Piasecka ${ }^{1}$ \\ ${ }^{1}$ Department of Histology and Developmental Biology, Pomeranian Medical University in Szczecin, Poland \\ ${ }^{2}$ VitroLive Fertility Clinic, Szczecin, Poland \\ ${ }^{3}$ Department of Gynecology, Endocrinology and Gynecological Oncology, Pomeranian Medical University, Szczecin, Poland \\ ${ }^{4}$ Healthcare Center Nowe Orlowo, Gdynia, Poland \\ ${ }^{5}$ Invicta Fertility Clinic, Gdansk, Poland
}

\begin{abstract}
Objectives: Supplementary assays are needed for determination of relationships between sperm biomarkers and fertility potential. Therefore, our research was designed to determine the extent of sperm DNA fragmentation (SDF) and establish a discriminating threshold of SDF for fertility potential.

Material and methods: Semen characteristics were evaluated according to World Health Organization recommendations, and SDF was assessed by sperm chromatin dispersion test on ejaculated spermatozoa from infertile and healthy normozoospermic men.

Results: A higher proportion of SDF was noted in infertile men (median 23.00\%) than normozoospermic (median 14.00\%). Significantly less subjects (17.03\%) with low SDF level ( $\leq 15 \%)$ and more $(35.17 \%)$ with high SDF level (> 30\%) were found for the infertile group vs the normooospermic ( $57.90 \%$ and $5.26 \%$, respectively). Infertile group had significantly lower odds ratio (OR) for having a low SDF level (OR: 0.1493) and higher OR for having a high SDF level (OR: 9.7627). Receiver operating characteristic analysis [area under curve $(A U C)=0.785$ ] revealed that $20 \%$ SDF is predictive value for discriminating between infertile and normozoospermic subjects. SDF was negatively correlated with the sperm number, morphology, progressive motility and vitality but positively with the teratozoospermia index.

Conclusions: Our study demonstrates: (1) a significant difference in the extent of SDF and in the risk for having damaged sperm DNA between infertile and normozoospermic men, (2) > 20\% SDF has negative predictive value for fertility potential, (3) coexistence of abnormal standard sperm parameters with sperm chromatin damages. Therefore, SDF should be considered as a highly valuable indicator of male fertility potential.
\end{abstract}

Key words: male infertility; semen parameters; sperm chromatin dispersion

Ginekologia Polska 2019; 90, 12: 684-691

\section{INTRODUCTION}

Currently, infertility is a rapidly growing global problem for affected couples, public health and the economy because society is ageing. Infertility is estimated to globally affect as many as 186 million people. Each year, approximately $15-20 \%$ of couples suffer from the inability to have child. Based on recent data, we can estimate that a male factor (coexisting with a female factor) contributes to half of these issues, and approximately $30 \%$ of these cases are related to isolated male factor [1,2]. Furthermore, male factors may be responsible for fertilization and embryo development failure, increases in the risk of idiopathic recurrent miscarriages and autosomal dominant diseases and neurobehavioural disorders in offspring, especially when the paternal age is taken into consideration $[3,4]$. Thus, the diagnosis and treatment of male infertility cannot be overlooked in the era of assisted reproductive technology (ART), especially for in vitro fertilization, where natural selection is almost bypassed. Therefore, new diagnostic tests are needed for the evaluation of sperm biomarkers, which have predictive value for reproductive success.

Sperm DNA fragmentation (SDF) is recognized as a comprehensive parameter that plays a key role in both natural and medically assisted procreation and can potentially contribute to reduced reproductive success. Generally, two hypothesis have been proposed to explain the pathogenesis of SDF. Both the intrinsic factors (i.e. genetic factors, abortive apoptosis and defective sperm maturation) and extrinsic 
factors (i.e. prolonged stasis during epididymal transit, varicocele, drug use, smoking, alcohol consumption, obesity, environmental pollution, systematic infection and diseases) contributing to pathological generation of reactive oxygen species are recognized as major causative factors of sperm chromatin damage [5].

However, the impact of SDF on reproductive outcomes is unclear. It should be highlighted that in many cases this impact is dependent on sperm chromatin abnormality levels. In this context, many authors try to find optimal threshold of SDF for assessment of male fertility potential [6-9]. It is suggested that low SDF level (0-15\% sperm cells with DNA fragmentation) corresponds to high fertility potential, moderate SDF level (16-30\%) to moderate fertility potential while high SDF level (>30\%) to low fertility potential $[7,10-12]$. The aim of this study was therefore to determine the extent of SDF and establish a discriminating threshold value of SDF for fertility potential.

\section{MATERIAL AND METHODS}

\section{Subjects}

The study was performed on semen samples obtained from subjects with abnormal standard semen parameters and proven infertility $(n=182$, median age $=33$ years $)$ and healthy volunteers with normal standard semen characteristics, i.e. normozoospermia $(n=114$, median age $=27$ years, potentially normal fertile status), at the Andrology Laboratory of Department of Histology and Developmental Biology (Pomeranian Medical University in Szczecin, Poland). The infertile group was created from couples who were treated/diagnosed for infertility. According to the World Health Organization (WHO) recommendations criteria of infertility, we considered cases that did not result in pregnancy after a minimum of 12 months of regular, unprotected sexual intercourse [13]. In some cases ( $n=46)$, male factors coexisted with female factors. For all participants, the exclusion criteria included: azoospermia; testicular injures, tumours or torsion incidences; co-existing systemic disease; and a history of mumps. The ethics committee of the Pomeranian Medical University, Szczecin, Poland approved the study protocol (ethical authorization number: KB-0012/88/11).

The semen samples were obtained by masturbation after 2-7 days of sexual abstinence. The standard semen characteristics were evaluated in accordance with WHO recommendations [13] (Tab. 1). Normozoospermia was considered according to the following criteria: total sperm cells count $\geq 39 \mathrm{mln}, \%$ of progressively motile sperm cells $\geq 32 \%$ and $\%$ of sperm cells with normal morphology $\geq 4 \%$. In the group of infertile men, the following seminological categories were distinguished: asthenozoospermia (\% of progressively motile sperm cells below the lower reference threshold, $n=2$ ); oligozoospermia (total number of sperm cells below the lower reference threshold, $n=4$ ); teratozoospermia (\% of morphologically normal spermatozoa below the lower reference threshold, $n=77$ ); asthenoteratozoospermia (\% of both progressively motile and morphologically normal sperm cells below the lower reference thresholds, $n=25$ ); oligoteratozoospermia (total number of spermatozoa and \% of morphologically normal spermatozoa below the lower reference thresholds, $n=36$ ) and oligoasthenoteratozoospermia (total number of spermatozoa, $\%$ of both progressively motile and morphologically normal spermatozoa below the lower reference thresholds, $n=38$ ).

\section{Sperm chromatin dispersion (SCD) test}

The SCD test was performed to evaluate SDF using a $\mathrm{Ha}$ losperm G2 kit (Halotech DNA, Madrid, Spain) following the manufacturer's guidelines and methodology, including calculation and interpretation of results which was described in our previous publications $[14,15]$.

\section{Statistical analyses}

The Statistica version 13.3 (StatSoft, Poland) and MedCalc version 15.2.2 (MedCalc Software, Belgium) software were used to perform statistical analyses. The quantitative variables are expressed as the mean \pm standard deviation (SD) and median (interquartile, range), while categorical data are reported as percentages. Normal distribution were assessed using Shapiro-Wilk test, while Mann-Whitney $U$ test was performed for comparison of two groups. $A X^{2}$ test was carried out to compare the categorical data. The interdependences of the variables were examined by calculating the rank Spearman correlation coefficient $\left(r_{s}\right)$. The odds ratios (OR) for SDF levels to define the risk in predicting the level of SDF in group of infertile men with respect to group of normozoospermic donors were calculated. Statistical significance for all testes was defined as a $p$ value of $<0.05$.

\section{RESULTS}

The characteristics and comparison (age and standard semen parameters) of healthy normozoospermic volunteers and infertile men with abnormal semen parameters are presented in Table 1. The proportion of sperm cells with DNA fragmentation was significantly lower $(p<0.000001)$ in the healthy volunteers than the infertile men (median: $14.00 \%$ vs $23.00 \%$, respectively) (Fig. 1 ).

Furthermore, the levels of sperm DNA fragmentation were designated based on the following criteria: low SDF level (0-15\% sperm cells with fragmented DNA, high fertility potential), moderate SDF level (16-30\%, moderate fertility potential) and high SDF level (> 30\%, low fertility potential) $[7,10-12]$. Healthy volunteers and infertile men differed significantly $(p<0.0001)$ at low levels $(57.90 \%$ vs $17.03 \%$ subjects, respectively) and high levels (5.26\% vs $35.17 \%$ 


\begin{tabular}{|c|c|c|c|}
\hline $\begin{array}{l}\text { Parameters } \\
\mathbf{n} \\
\text { median (range) } \\
\text { mean } \pm \text { SD }\end{array}$ & Total & Infertile men & Health volunteers \\
\hline Age [y] & $\begin{array}{l}n=296 \\
31.00(19.00-54.00) \\
31.19 \pm 6.12\end{array}$ & $\begin{array}{l}n=182 \\
33.00(21.00-54.00) \\
33.45 \pm 5.52\end{array}$ & $\begin{array}{l}n=114 \\
27.00(19.00-45.00) \\
27.57 \pm 5.25\end{array}$ \\
\hline Semen volume [mL] & $\begin{array}{l}n=296 \\
3.50(0.50-10.00) \\
3.70 \pm 1.67\end{array}$ & $\begin{array}{l}n=182 \\
3.00(0.50-9.00) \\
3.41 \pm 1.59\end{array}$ & $\begin{array}{l}n=114 \\
4.00(1.00-10.00) \\
4.16 \pm 1.70\end{array}$ \\
\hline Sperm concentration $\left[\times 10^{6} / \mathrm{mL}\right]$ & $\begin{array}{l}n=296 \\
20.76(0.40-283.00) \\
28.60 \pm 29.94\end{array}$ & $\begin{array}{l}n=182 \\
14.44(0.40-147.50) \\
23.80 \pm 25.96\end{array}$ & $\begin{array}{l}n=114 \\
29.90(8.25-283.00) \\
36.28 \pm 34.12\end{array}$ \\
\hline $\begin{array}{l}\text { Total number of spermatozoa [ } \mathrm{x} \\
\left.10^{6}\right]\end{array}$ & $\begin{array}{l}n=296 \\
70.11(0.89-566.00) \\
98.87 \pm 94.82\end{array}$ & $\begin{array}{l}n=182 \\
47.00(0.89-489.00) \\
78.87 \pm 18.00\end{array}$ & $\begin{array}{l}n=114 \\
105.60(39.00-566.00) \\
139.23 \pm 104.09\end{array}$ \\
\hline $\begin{array}{l}\text { Morphologically normal } \\
\text { spermatozoa [\%] }\end{array}$ & $\begin{array}{l}n=296 \\
2.00(0.00-15.00) \\
3.24 \pm 3.05\end{array}$ & $\begin{array}{l}n=182 \\
1.00(0.00-7.00) \\
1.24 \pm 1.31\end{array}$ & $\begin{array}{l}n=114 \\
6.00(4.00-15.00) \\
6.42 \pm 2.22\end{array}$ \\
\hline TZI & $\begin{array}{l}n=296 \\
1.50(1.20-2.30) \\
1.55 \pm 0.18\end{array}$ & $\begin{array}{l}n=182 \\
1.61(1.20-2.30) \\
1.62 \pm 0.19\end{array}$ & $\begin{array}{l}n=114 \\
1.43(1.23-1.67) \\
1.62 \pm 0.19\end{array}$ \\
\hline Progressive motility [\%] & $\begin{array}{l}n=296 \\
53.00(0.00-86.00) \\
49.28 \pm 21.34\end{array}$ & $\begin{array}{l}n=182 \\
41.00(0.00-81.00) \\
39.23 \pm 19.88\end{array}$ & $\begin{array}{l}n=114 \\
65.00(32.00-86.00) \\
65.30 \pm 11.59\end{array}$ \\
\hline Non-progressive motility [\%] & $\begin{array}{l}n=296 \\
7.00(0.00-26.00) \\
7.50 \pm 4.53\end{array}$ & $\begin{array}{l}n=182 \\
6.00(0.00-26.00) \\
6.57 \pm 4.50\end{array}$ & $\begin{array}{l}n=114 \\
8.00(0.00-23.00) \\
9.05 \pm 4.16\end{array}$ \\
\hline $\begin{array}{l}\text { Eosin-negative spermatozoa } \\
\text { — live cells [\%] }\end{array}$ & $\begin{array}{l}n=296 \\
78.00(0.00-95.00) \\
73.78 \pm 15.60\end{array}$ & $\begin{array}{l}n=182 \\
74.00(0.00-91.00) \\
81.50 \pm 8.44\end{array}$ & $\begin{array}{l}n=114 \\
83.00(48.00-95.00) \\
68.92 \pm 17.06\end{array}$ \\
\hline $\begin{array}{l}\text { HOS test-positive spermatozoa } \\
\text { — live cells [\%] }\end{array}$ & $\begin{array}{l}n=271 \\
77.00(0.00-94.00) \\
73.14 \pm 15.90\end{array}$ & $\begin{array}{l}n=157 \\
72.00(0.00-88.00) \\
81.38 \pm 8.24\end{array}$ & $\begin{array}{l}n=114 \\
83.00(50.00-94.00) \\
67.15 \pm 17.40\end{array}$ \\
\hline Peroxidase-positive cells [m/n/mL] & $\begin{array}{l}n=296 \\
0.10(0.00-10.00) \\
0.37 \pm 0.86\end{array}$ & $\begin{array}{l}n=182 \\
0.25(0.00-10.00) \\
1.04 \pm 0.00\end{array}$ & $\begin{array}{l}n=114 \\
0.00(0.00-1.50) \\
0.24 \pm 0.00\end{array}$ \\
\hline
\end{tabular}

$\mathrm{n}$ - number of subjects; SD — standard deviation; HOS test - hypo-osmotic swelling test; TZI — teratozoospermia index

subjects, respectively) of SDF (Tab. 2). Additionally, the group of infertile men had significantly lower odds ratio (OR) for having a low SDF level (OR: 0.1493) and higher ORs for having a high SDF level (OR: 9.7627) vs the men from group of healthy volunteers (Tab. 3).

Based on receiver operating characteristic (ROC) analysis, suggested optimal SDF threshold of 20\% [area under curve $(A \cup C)=0.785, p<0.001$ ] was estimated to distinguish between infertile men with abnormal standard semen parameters and healthy normozoospermic men (Fig. 2). Furthermore, prevalence of men with $>20 \%$ SDF was significantly higher in infertile men vs the men from group of healthy volunteers (63.74\% vs $21.05 \%$, respectively) (Tab. 4). Moreover, infertile men had higher ORs for having $>20 \%$ SDF (OR: 6.5909) vs healthy volunteers (Tab. 5).
SDF positively correlated with male age $\left(r_{s}=0.342\right)$, teratozoospermia index $\left(r_{s}=0.433\right)$ and peroxidase-positive cells $\left(r_{s}=0.203\right)$ but negatively correlated with sperm concentration $\left(r_{s}=-0.289\right)$, total number of spermatozoa $\left(r_{s}=-0.243\right)$, sperm morphology $\left(r_{s}=-0.533\right)$, sperm progressive motility $\left(r_{s}=-0.554\right)$, and eosin-negative and HOS test-reactive sperm cells $\left(r_{s}=-0.492\right.$ and $r_{s}=-0.535$, respectively) (Tab. 6).

\section{DISCUSSION}

\section{SDF measured by the Halosperm test reflects male fertility potential}

The clinical significance and recommendations of sperm chromatin integrity are still not completely understood. However, the analysis of SDF is recommended and has a clinical predictive value in cases of varicocele, particu- 


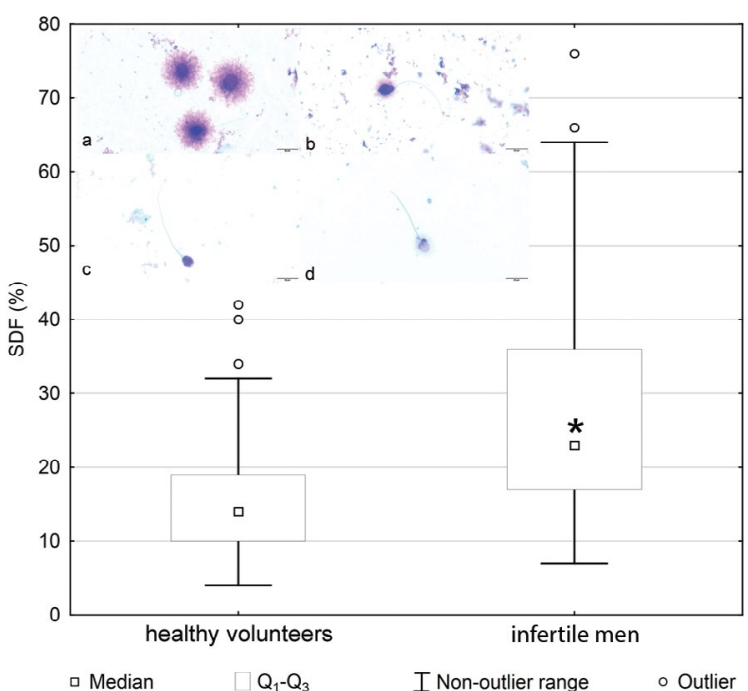

Figure 1. Comparison of sperm DNA fragmentation (SDF) in healthy volunteers $(n=114)$ and infertile men $(n=182) ; *$ - significant difference at $\mathrm{p}<0.000001 ; \mathrm{Q} 1-\mathrm{Q} 3$ - lower-upper quartile; Mann-Whitney $U$ test; Insert — results of sperm chromatin dispersion test: sperm cells without fragmented nuclear DNA (a), with fragmented nuclear DNA (b, c) and degraded DNA (d); Scale bar $=20 \mu \mathrm{m}$

Table 2. Prevalence of sperm chromatin fragmentation (SDF) levels in group of infertile man with abnormal standard semen parameters $(n=182)$ and group of healthy volunteers with normal standard semen parameters $(n=114)$

\begin{tabular}{|l|l|l|l|}
\hline \multirow{2}{*}{ Group } & \multicolumn{3}{|l|}{ SDF [\%] } \\
\cline { 2 - 4 } & $\begin{array}{l}\mathbf{0 - 1 5 \%} \\
\mathbf{n}(\%)\end{array}$ & $\begin{array}{l}\mathbf{1 6 - 3 0 \%} \\
\mathbf{n}(\%)\end{array}$ & $\begin{array}{l}>\mathbf{3 0 \%} \\
\mathbf{n}(\%)\end{array}$ \\
\hline Infertile men & $31(17.03)^{*}$ & $87(47.80)$ & $64(35.17)^{*}$ \\
\hline Healthy volunteers & $66(57.90)$ & $42(36.84)$ & $6(5.26)$
\end{tabular}

$\mathrm{n}$ - number of subjects; ${ }^{*}$ - significant difference between compared groups at $\mathrm{p}<0.0001 ; \mathrm{Chi}^{2}$ test

Table 3. Odds ratio (OR) for sperm chromatin fragmentation (SDF) levels in the group of infertile men with abnormal standard semen characteristics $(n=182)$ and group of healthy normozoospermic volunteers $(n=114)$

\begin{tabular}{|c|c|c|c|}
\hline & Infertile men & Healthy volunteers & OR $(95 \% \mathrm{Cl})$ \\
\hline $\begin{array}{l}\text { SDF } \\
0-15 \%\end{array}$ & $31(17.03)$ & $66(57.90)$ & $\begin{array}{l}0.1493^{*} \\
(0.0873-0.2553)\end{array}$ \\
\hline $\begin{array}{l}\text { SDF } \\
16-30 \%\end{array}$ & $87(47.80)$ & $42(36.84)$ & $\begin{array}{l}1.5699 \\
(0.9724-2.5345)\end{array}$ \\
\hline $\begin{array}{l}\text { SDF } \\
>30 \%\end{array}$ & 64 (35.17) & $6(5.26)$ & $\begin{array}{l}9.7627^{*} \\
(4.0632-23.4569)\end{array}$ \\
\hline
\end{tabular}

$\mathrm{n}-$ number of subjects; ${ }^{*}-$ statistical significance at $\mathrm{p}<0.0001$; $95 \% \mathrm{Cl}-95 \%$ confidential interval

larly for varicocelectomy, unexplained infertility, recurrent pregnancy loss, unsuccessful ART procedures, unhealthy lifestyle and advanced male age. Knowledge about the scale

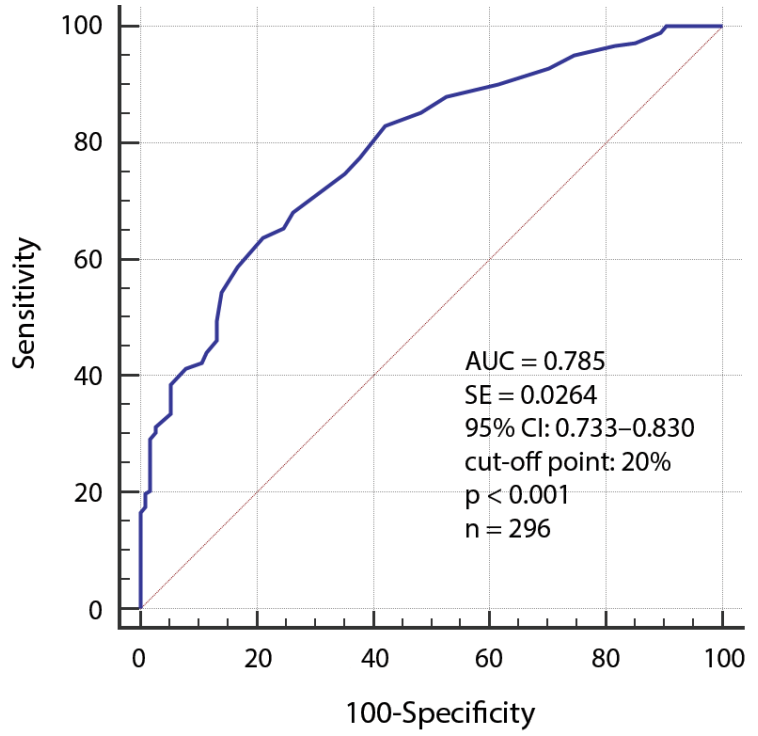

Figure 2. Receiver operating characteristic $(\mathrm{ROC})$ curve of sperm DNA fragmentation for predicting male fertility potential; AUC - area under the curve; $\mathrm{p} \leq 0.05$ - statistical significance between obtained AUC vs AUC $=0.5 ; 95 \% \mathrm{Cl}-95 \%$ confidence interval; SE - standard error; The following level of AUC were presumed: $>0.7-0.8$ - satisfactory predictive value

Table 4. Prevalence of sperm chromatin fragmentation (SDF) levels in group of infertileman with abnormal standard semen parameters $(n=182)$ and group of healthy volunteers with normal standard semen parameters $(n=114)$

\begin{tabular}{|l|l|l|}
\hline \multirow{2}{*}{ Group } & \multicolumn{2}{|l}{ SDF [\%] } \\
\cline { 2 - 3 } & $\begin{array}{l}\mathbf{0 - 2 0 \%} \\
\mathbf{n}(\%)\end{array}$ & $\begin{array}{l}\mathbf{2 0 \%} \\
\mathbf{n}(\%)\end{array}$ \\
\hline Infertile men & $66(36.26)^{*}$ & $116(63.74)^{*}$ \\
\hline Healthy volunteers & $90(78.95)$ & $24(21.05)$
\end{tabular}

$\mathrm{n}$ - number of subjects; ${ }^{*}$ - significant difference between compared groups at $\mathrm{p}<0.0001 ; \mathrm{Chi}^{2}$ test

of DNA abnormalities play a key role in the development of an optimal treatment algorithm for male infertility $[5,16,17]$.

Generally, sperm cells with $>30 \%$ immature chromatin is a cut-off point for a high risk of infertility $[6-8,10-12,18]$. Bungum et al. [18] showed that in the range of $0-20 \%$ sperm DNA fragmentation, the chance of a spontaneous pregnancy was constant, while DNA fragmentation index (DFI) levels $>30-40 \%$ resulted in reduced chances close to zero. However, these 2 categories can reasonably be extended to 3, as proposed by Leach et al. [7], Abdelbaki et al. [10] and Al Omrani et al. [12]. In this division, a threshold of $0-15 \%$ is considered a high fertility potential, while $16-30 \%$ and $>30 \%$ are considered moderate and low fertility potentials, respectively. Likewise, in our present group of infertile patients, $35.17 \%$ of the subjects exhibited a high level of SDF (> 30\%) compared to $5.26 \%$ of the subjects in the healthy normozoospermic group. An inverse relationship was found 
Table 5. Odds ratio (OR) for sperm chromatin fragmentation (SDF) levels in the group of infertile men with abnormal standard semen characteristics $(n=182)$ and group of healthy normozoospermic volunteers $(n=114)$

\begin{tabular}{|l|l|l|l|}
\hline & Infertile men & Healthy volunteers & OR (95\% CI) \\
\hline SDF $>\mathbf{2 0 \%}$ & $116(63.74)$ & $24(21.05)$ & $\mathbf{6 . 5 9 0 9 * ( 3 . 8 3 2 1 - 1 1 . 3 3 5 9 )}$ \\
\hline
\end{tabular}

$\mathrm{n}$ - number of subjects; ${ }^{*}$ - statistical significance at $\mathrm{p}<0.0001 ; 95 \% \mathrm{Cl}-95 \%$ confidential interval

Table 6. Rank Spearman correlations $\left(r_{s}\right)$ between human sperm chromatin fragmentation (SDF), male age and standard semen parameters $(n=296)$

\begin{tabular}{|c|c|}
\hline Parameters & SDF \\
\hline Age [y] & $\begin{array}{l}0.342 \\
p<0.000001\end{array}$ \\
\hline Semen volume [mL] & $\begin{array}{l}-0.009 \\
p=0.872\end{array}$ \\
\hline Sperm concentration $\left[\times 10^{6} / \mathrm{mL}\right]$ & $\begin{array}{l}-0.289 \\
p<0.000001\end{array}$ \\
\hline Total number of spermatozoa $\left[\times 10^{6}\right]$ & $\begin{array}{l}-0.243 \\
p=0.000023\end{array}$ \\
\hline Morphologically normal spermatozoa [\%] & $\begin{array}{l}-0.533 \\
p<0.000001\end{array}$ \\
\hline TZI & $\begin{array}{l}0.433 \\
p<0.000001\end{array}$ \\
\hline Progressive motility [\%] & $\begin{array}{l}-0.554 \\
p<0.000001\end{array}$ \\
\hline Non-progressive motility [\%] & $\begin{array}{l}-0.137 \\
p=0.019\end{array}$ \\
\hline Eosin-negative spermatozoa - live cells [\%] & $\begin{array}{l}-0.492 \\
p<0.000001\end{array}$ \\
\hline HOS test-positive spermatozoa - live cells [\%] & $\begin{array}{l}-0.535 \\
p<0.000001\end{array}$ \\
\hline Peroxidase-positive cells [mln/mL] & $\begin{array}{l}0.203 \\
p=0.0004\end{array}$ \\
\hline
\end{tabular}

The interpretation of rs value: $<0.2$ lack of linear dependence, $0.2-0.4-$ weak dependence, $0.4-0.7$ - moderate dependence, $0.7-0.9$ - strong dependence, $>0.9$ - very strong dependence; SDF — sperm chromatin fragmentation; $n-$ number of subjects, statistical significance at $p<0.05$ HOS test — hypo-osmotic swelling test, TZI — teratozoospermia index

for the low level of sperm DNA fragmentation (0-15\%), only $17.03 \%$ of men in the infertile group and $57.90 \%$ of men in the control group had low levels. Furthermore, the ORs for having a low SDF level or high SDF level significantly discriminated infertile men from healthy volunteers. Infertile men were morethan six times as likely to have not a low SDF level (OR: 0.1493) and had more than nine times the risk for having a high SDF level (OR: 9.7627). The prevalence of sperm chromatin damage revealed in our study was consistent with the Mann-Whitney $U$ test results. In this study, the median value of SDF was significantly higher in the infertile group than the control group (median $23.00 \%$ vs $14.00 \%$ ).

On the other hand, ROC analysis used to examine the frequency distribution of the SDF results, provided new data. Suggested optimal SDF threshold to distinguish between healthy normozoospermic men and infertile men was $20 \%$. The prevalence of men with $>20 \%$ SDF was significantly higher and OR for having > 20\% SDF was over six-times higher in infertile men vs healthy volunteers. Therefore, we can conclude that $>20 \%$ SDF has negative predictive value for male fertility potential. It should be emphasized that suggested threshold value of $20 \%$ SDF differs from the value given by the Halosperm G2 kit manufacturer (30\% SDF). Therefore, our results may suggest that men with 20-30\% SDF can be incorrectly classified as a men with normal fertility potential.

Presented above results are in agreement with data from other authors. Marchlewska et al. [19] reported that men from infertile couples had $28.00 \%$ spermatozoa with SDF. Majzoub et al. [20] revealed significant differences in SDF between infertile and fertile men (mean: $27.60 \pm 1.02 \%$ vs $15.68 \pm 0.92 \%)$. In turn, Wiweko and Utami [9] demonstrated not only significant differences in SDF between infertile and fertile men (median $29.9 \%$ vs $19.9 \%$ ) but also the ability of SDF to diagnose male infertility by an ROC curve. In addition, Tandara et al [21] showed the useful predictive value of SDF for fertilization. Moreover, Zheng et al. [22] observed that patients in a pregnant group had significantly lower levels of SDF than patients without reproductive success (mean: $24.41 \pm 7.24 \%$ vs $29.95 \pm 11.20$ ). Furthermore, patients who had sperm DNA damage $\leq 10 \%$ had a higher good embryo rate, blastocyst formation rate, implantation rate and clinical pregnancy rate than those who had $\geq 21 \%$ sperm DNA damage. In the group with better DNA integrity, a lower abortion rate was observed. A compatible significance of the Halosperm test during ICSI was presented by Sivanarayana et al. [23] who divided patients into groups with $\geq 30 \%$ or $<30 \%$ SDF. The authors discovered connections between SDF and standard semen parameters (men from group $\geq 30 \%$ SDF had significantly lower semen quality) and clinical outcomes. A higher level of SDF is associated with a reduced number of 8 -cell embryos on the $3^{\text {rd }}$ day after fertilization and the number of blastocysts formed on the $5^{\text {th }}$ day in addition to lower clinical pregnancy and delivery rates and a higher miscarriage rate. Furthermore, Khadem et al. [24] discovered that men from couples with recurrent, spontaneous abortion had significantly higher levels of SDF than those of the control group (mean $43.3 \%$ vs $16.7 \%$ ). Additionally, Absalan et al. [25] reported similar results; i.e., men from couples with unexplained, recurrent abortion 
had significantly higher proportions of sperm cells without halos (degenerated DNA) than healthy volunteers (mean: $23.26 \pm 1.10 \%$ vs $11.60 \pm 0.50 \%$ ) and lower proportions of spermatozoa with large halos (without DNA fragmentation) ( $41.40 \pm 1.43$ vs $65.93 \pm 2.35 \%)$. In contrast, Coughlan et al. [26] observed the ambiguous influence of SDF. Men from couples with recurrent implantation failure had $20.1 \pm 2.9 \%$ sperm cells with DNA damage, and subjects from couples with recurrent miscarriage had $15.1 \pm 3.6 \%$ vs men with proven fertility $(16.4 \pm 3.7 \%)$. Thus, based on the described data, SDF measured by the Halo test can reasonably be assumed to reflect male fertility potential.

\section{Relationships between human standard semen characteristics and sperm chromatin dispersion}

Moreover, our study exhibited significant correlations between SDF and age, sperm concentration, total number of spermatozoa, sperm cell morphology, teratozoospermia index (TZI), sperm cell progressive motility, vitality and concentration of peroxidase-positive cells in ejaculate. Other authors also indicate similar correlations. Significant associations were found between sperm cells with large halos and the sperm concentration, motility, morphology and vitality $(r=0.26, r=0.37, r=0.43$ and $r=0.49$, respectively) but not the fertilization rate $(r=0.01)$ [21]. Additionally, Khadem et al. [24] showed a significant correlation between SDF and sperm cell motility and morphology ( $r=-0.613$ and $r=-0.764$, respectively). Moreover, Majoub et al. [20] presented relationships between SDF and normal sperm morphology in groups of infertile and fertile men $\left(r_{s}=-0.351\right.$ and $r_{s}=-0.257$, respectively), especially with head defects $\left(r_{s}=0.438\right.$ and $r_{s}=0.366$, respectively). Similarly, Fortunato et al. [27] found a correlation between SDF and the percentage of normal sperm cells formed and multiple morphological abnormalities $(r=-0.283$ and $r=0.233$, respectively). Another study revealed correlations between SDF and sperm motility and morphology $(r=-0.282$ and $r=-0.340$, respectively) and between SDF and the percentage of normal $X$ or $Y$ sperm chromosome $(r=-0.559)$ [28]. Furthermore, Zheng et al. [22] showed negative correlations between SDF results and the good embryo rate $\left(r_{s}=-0.330\right)$, blastocyst formation rate $\left(r_{s}=-0.320\right)$, embryo implantation $\left(r_{s}=-0.208\right)$, and clinical pregnancy $\left(r_{s}=-0.221\right)$. The described findings suggest a relationship exists between standard semen and SDF that affects male fertility potential. Therefore, efforts to improve sperm quality are justified under natural conditions and medically assisted reproduction.

\section{Limitations and strengths of the study}

This study was not without limitations. As a control group we considered a healthy normozoospermic volunteers who declared no problems with conception, chronic diseases, trauma of testis or any other factors which could affect male fertility. Therefore, we presume that this group presented normal fertility potential. On the other hand, we cannot be sure that all of them were fertile. Another known limitation is associated with SCD method which was perform to evaluation of sperm DNA integrity. SCD is not a direct method of DNA breaks assessment in contrast to comet assay, TUNEL or SCSA [6, 29-31], but yet this method has some significant diagnostic and clinical advantages. Halosperm $\mathrm{G} 2$ is ready to use kit which minimizes the risk of mistakes and positive or negative false results. Also methodology is easy to perform and not required more than basic laboratory skills. Moreover, SCD seems to be economically justified because for visualization of SDF uses simple light microscope in opposition to TUNEL or SCSA methods where application of expensive flow cytometer is required $[6,14,15]$. As forother strengths of our study, we wanted to highlighted some facts. Despite that our control group does not contain only men with proven fertile status, our results of SDF assessment were in agreement with other researchers, who have shown that clinically significant threshold to discriminated men with proven fertility from infertile men is approximately $15-20 \%[18,19,32,33]$. Moreover, all participants both normozoospermic volunteers and diagnosed infertile patients came to the same laboratory and the analysis of their semen was carried out in exactly the same way. Furthermore, semen assessment took only one year. We believe that such a short period of time should eliminate the impact of external factors like environmental pollution, unhealthily diet or life style trends which may change over the years. It seems to be important, because many authors underline alarming trend in decline of semen quality visible every few years [34].

\section{CONCLUSIONS}

Our paper highlighted that: 1) abnormal standard sperm parameters coexist with sperm chromatin abnormalities, 2) the risk for having a high level of sperm DNA damage increases when conventional sperm characteristics are reduced, 3 ) > 20\% SDF (our calculated cut-off point) has negative predictive value for male fertility potential, 4) the men with $20-30 \%$ SDF should be considered as a men with a risk of reduced fertility potential. Therefore, routinely incorporating sperm chromatin dispersion testing into the evaluation of male fertility potential is important and will allow an opportunity for correct therapeutic management to potentially restore the natural fertility of a patient, enroll them in ART procedures, or exclude them from ART procedures due to the high level of DNA damage.

It should be underlined that in case of high SDF levels some authors suggest possible treatment strategies to reduce SDF (e.g. lifestyle modifications, treatment of varicocele and urogenital infections, antioxidants therapy) and in- 
crease the chance to achieve pregnancy by natural conception or ART $[5,17,35]$. The effects of the treatment should be evaluated after 3 months (duration of spermatogenesis and two weeks of sperm cells transit through the epididymis). On the other hand, long time of sexual abstinence is negatively associated with sperm integrity and it is worth to evaluate SDF levels after short sexual abstinence time, which can be especially important in case of ART. Therefore, the algorithm indicates the need to repeat SDF analysis and based on the new diagnostic data preferential and individual therapeutic strategy should be made $[5,17,35-37]$.

\section{Funding}

This work was supported by the Pomeranian Medical University in Szczecin, Szczecin, Poland. Grant no. WNoZ-32204/S/16/2019 and under grant no. FSN-322-5/2016.

\section{REFERENCES}

1. Inhorn MC, Patrizio P. Infertility around the globe: new thinking on gender, reproductive technologies and global movements in the $21 \mathrm{st}$ century. Hum Reprod Update. 2015; 21(4): 411-426, doi: 10.1093/humupd/dmv016, indexed in Pubmed: 25801630.

2. Pan MM, Hockenberry MS, Kirby EW, et al. Male Infertility Diagnosis and Treatment in the Era of In Vitro Fertilization and Intracytoplasmic Sperm Injection. Med Clin North Am. 2018; 102(2): 337-347, doi: 10.1016/j. mcna.2017.10.008, indexed in Pubmed: 29406062.

3. Kazerooni T, Asadi N, Jadid L, et al. Evaluation of sperm's chromatin quality with acridine orange test, chromomycin $\mathrm{A} 3$ and aniline blue staining in couples with unexplained recurrent abortion. J Assist Reprod Genet. 2009; 26(11-12): 591-596, doi: 10.1007/s10815-009-9361-3, indexed in Pubmed: 19894107.

4. Sharma R, Agarwal A, Rohra VK, et al. Effects of increased paternal age on sperm quality, reproductive outcome and associated epigenetic risks to offspring. Reprod Biol Endocrinol. 2015; 13: 35, doi: 10.1186/s12958015-0028-x, indexed in Pubmed: 25928123.

5. Cho $\mathrm{CL}$, Agarwal A. Role of sperm DNA fragmentation in male factor infertility: A systematic review. Arab J Urol. 2018; 16(1): 21-34, doi: 10.1016/j.aju.2017.11.002, indexed in Pubmed: 29713533.

6. Evenson DP. Evaluation of sperm chromatin structure and DNA strand breaks is an important part of clinical male fertility assessment. Transl Androl Urol. 2017; 6(Suppl 4): S495-S500, doi: 10.21037/tau.2017.07.20, indexed in Pubmed: 29082168.

7. Leach M, Aitken RJ, Sacks G. Sperm DNA fragmentation abnormalities in men from couples with a history of recurrent miscarriage. Aust $\mathrm{N}$ Z J Obstet Gynaecol. 2015; 55(4): 379-383, doi: 10.1111/ajo.12373, indexed in Pubmed: 26201831.

8. Simon L, Emery BR, Carrell DT. Review: Diagnosis and impact of sperm DNA alterations in assisted reproduction. Best Pract Res Clin Obstet Gynaecol. 2017; 44:38-56, doi: 10.1016/j.bpobgyn.2017.07.003, indexed in Pubmed: 28935366.

9. Wiweko B, Utami P. Predictive value of sperm deoxyribonucleic acid (DNA) fragmentation index in male infertility. Basic Clin Androl. 2017; 27: 1, doi: 10.1186/s12610-016-0046-3, indexed in Pubmed: 28239474.

10. Abdelbaki SA, Sabry JH, Al-Adl AM, et al. The impact of coexisting sperm DNA fragmentation and seminal oxidative stress on the outcome of varicocelectomy in infertile patients: A prospective controlled study. Arab J Urol. 2017; 15(2): 131-139, doi: 10.1016/j.aju.2017.03.002, indexed in Pubmed: 29071142.

11. Evenson DP, Larson $\mathrm{KL}$, Jost LK. Sperm chromatin structure assay: its clinical use for detecting sperm DNA fragmentation in male infertility and comparisons with other techniques. J Androl. 2002; 23(1): 25-43, doi: 10.1002/j.1939-4640.2002.tb02599.x, indexed in Pubmed: 11780920.

12. Al Omrani B, Al Eisa $N$, Javed $M$, et al. Associations of sperm DNA fragmentation with lifestyle factors and semen parameters of Saudi men and its impact on ICSI outcome. Reprod Biol Endocrinol. 2018; 16(1): 49, doi: 10.1186/s12958-018-0369-3, indexed in Pubmed: 29778100.
13. World Health Organization. 2010. WHO Laboratory Manual for the Examination and Processing of Human Semen. 5th ed. World Health Organization Press, Geneva.

14. Gill K, Jakubik J, Kups M, et al. The impact of sedentary work on sperm nuclear DNA integrity. Folia Histochem Cytobiol. 2019; 57(1): 15-22, doi: 10.5603/FHC.a2019.0002, indexed in Pubmed: 30869154.

15. Gill K, Jakubik J, Rosiak-Gill A, et al. Utility and Predictive Value of Human Standard Semen Parameters and Sperm DNA Dispersion for Fertility Potential. Int J Environ Res Public Health. 2019; 16(11), doi: 10.3390/ijerph16112004, indexed in Pubmed: 31195656.

16. Cho CL, Agarwal A, Majzoub A, et al. Clinical utility of sperm DNA fragmentation testing: concise practice recommendations. Transl Androl Urol. 2017; 6(Suppl 4): S366-S373, doi: 10.21037/tau.2017.07.28, indexed in Pubmed: 29082146.

17. Majzoub A, Agarwal A, Esteves SC. Clinical utility of sperm DNA damage in male infertility. Panminerva Med. 2019; 61(2): 118-127, doi: 10.23736/S0031-0808.18.03530-9, indexed in Pubmed: 30990284.

18. Bungum $M$, Bungum $L$, Giwercman A. Sperm chromatin structure assay (SCSA): a tool in diagnosis and treatment of infertility. Asian J Androl. 2011; 13(1): 69-75, doi: 10.1038/aja.2010.73, indexed in Pubmed: 21057512.

19. Marchlewska K, Filipiak E, Walczak-Jedrzejowska R, et al. Sperm DNA Fragmentation Index and Hyaluronan Binding Ability in Men from Infertile Couples and Men with Testicular Germ Cell Tumor. Biomed Res Int. 2016; 2016: 7893961, doi: 10.1155/2016/7893961, indexed in Pubmed: 27999814.

20. Majzoub A, Arafa M, Mahdi M, et al. Oxidation-reduction potentia and sperm DNA fragmentation, and their associations with sperm morphological anomalies amongst fertile and infertile men. Arab J Urol. 2018; 16(1): 87-95, doi: 10.1016/j.aju.2017.11.014, indexed in Pubmed: 29713539.

21. Tandara M, Bajić A, Tandara L, et al. Sperm DNA integrity testing: big halo is a good predictor of embryo quality and pregnancy after conventional IVF. Andrology. 2014; 2(5): 678-686, doi: 10.1111/j.2047-2927.2014.002 34.x, indexed in Pubmed: 24947544.

22. Zheng WW, Song Ge, Wang QL, et al. Sperm DNA damage has a negative effect on early embryonic development following fertilization. Asian J Androl. 2018; 20(1): 75-79, doi: 10.4103/aja.aja_19_17, indexed in Pubmed: 28675153.

23. Sivanarayana T, Ravi Krishna Ch, Jaya Prakash G, et al. Sperm DNA fragmentation assay by sperm chromatin dispersion $(\mathrm{SCD})$ : correlation between DNA fragmentation and outcome of intracytoplasmic sperm injection. Reprod Med Biol. 2014; 13(2): 87-94, doi: 10.1007/s12522-0130168-7, indexed in Pubmed: 29699153.

24. Khadem N, Poorhoseyni A, Jalali M, et al. Sperm DNA fragmentation in couples with unexplained recurrent spontaneous abortions. Andrologia. 2014; 46(2): 126-130, doi: 10.1111/and.12056, indexed in Pubmed: 23278374.

25. Absalan F, Ghannadi A, Kazerooni M, et al. Value of sperm chromatin dispersion test in couples with unexplained recurrent abortion. J Assist Reprod Genet. 2012; 29(1): 11-14, doi: 10.1007/s10815-011-9647-0, indexed in Pubmed: 22009642.

26. Coughlan C, Clarke H, Cutting R, et al. Sperm DNA fragmentation, recurrent implantation failure and recurrent miscarriage. Asian J Androl. 2015; 17(4): 681-685, doi: 10.4103/1008-682X.144946, indexed in Pubmed: 25814156.

27. Fortunato A. Sperm DNA Fragmentation Assays Correlate with Sperm Abnormal Morphology and the Pregnancy Outcome. Journal of Fertilization: In Vitro - IVF-Worldwide, Reproductive Medicine, Genetics \& Stem Cell Biology. 2013; 01(01), doi: 10.4172/2375-4508.1000101.

28. Kim SW, Jee BC, Kim SKi, et al. Sperm DNA fragmentation and sex chromosome aneuploidy after swim-up versus density gradient centrifugation. Clin Exp Reprod Med. 2017; 44(4): 201-206, doi: 10.5653/cerm.2017.44.4.201, indexed in Pubmed: 29376017.

29. Ribas-Maynou J, Fernández-Encinas A, García-Peiró A, et al. Human semen cryopreservation: a sperm DNA fragmentation study with alkaline and neutral Comet assay. Andrology. 2014; 2(1): 83-87, doi: 10.1111/j.2 047-2927.2013.00158.x, indexed in Pubmed: 24255006.

30. Javed A, Talkad MS, Ramaiah MK. Evaluation of sperm DNA fragmentation using multiple methods: a comparison of their predictive power for male infertility. Clin Exp Reprod Med. 2019; 46(1): 14-21, doi: 10.5653/cerm.2019.46.1.14, indexed in Pubmed: 30827073.

31. Evgeni E, Charalabopoulos K, Asimakopoulos B. Human sperm DNA fragmentation and its correlation with conventional semen parameters. J Reprod Infertil. 2014; 15(1): 2-14, indexed in Pubmed: 24696791. 
32. Bungum $M$, Humaidan $P, A x m o n A$, et al. Sperm DNA integrity assessment in prediction of assisted reproduction technology outcome. Hum Reprod. 2007; 22(1):174-179, doi:10.1093/humrep/del326, indexed in Pubmed: 16921163.

33. Giwercman A, Lindstedt L, Larsson $M$, et al. Sperm chromatin structure assay as an independent predictor of fertility in vivo: a case-control study. Int J Androl. 2010; 33(1): e221-e227, doi: 10.1111/j.1365-2605. 2009.00995.x, indexed in Pubmed: 19840147.

34. Wang Li, Zhang $\mathrm{L}$, Song $\mathrm{XH}$, et al. Decline of semen quality among Chinese sperm bank donors within 7 years (2008-2014). Asian J Androl. 2017; 19(5): 521-525, doi: 10.4103/1008-682X.179533, indexed in Pubmed: 27345004.
35. Esteves SC. Interventions to Prevent Sperm DNA Damage Effects on Reproduction. Adv Exp Med Biol. 2019; 1166: 119-148, doi: 10.1007/9783-030-21664-1 8, indexed in Pubmed: 31301050.

36. Pons I, Cercas R, Villas $C$, et al. One abstinence day decreases sperm DNA fragmentation in $90 \%$ of selected patients. J Assist Reprod Genet. 2013; 30(9): 1211-1218, doi: 10.1007/s10815-013-0089-8, indexed in Pubmed: 23996278.

37. Agarwal A, Gupta S, Du Plessis S, et al. Abstinence Time and Its Impact on Basic and Advanced Semen Parameters. Urology. 2016; 94: 102-110, doi: 10.1016/j.urology.2016.03.059, indexed in Pubmed: 27196032 